\title{
Regulation of Pigment Migration in the Amphibian Melanophore
}

\author{
A. C. J. BURGERS aNd G. J. VAN OORDT \\ Zoological Laboratory, Department of Endocrinology, University of Utrecht, The Netherlands
}

\section{INTRODUCTION}

Among vertebrates rapid color changes in the skin are restricted to fishes, amphibia and reptiles. These reactions are based on the movements of pigment granules in special cells, the chromatophores which may be classified as leucophores, xanthophores, erythrophores and melanophores.

It is generally agreed that these chromatophores have a fixed outline and that the pigment granules can migrate from the center towards the periphery, and vice versa; for these migrations the terms pigment dispersion and pigment concentration will be employed.

The pigment migration processes in the melanophore are of a complex nature; they are influenced among others by the statoelectric condition of the cell-membrane and the gel- or sol-phase of the cell-plasm.

Various stimuli like light and humidity, as well as nervous and hormonal factors play an important role in the regulation of the pigment migrating processes in the melanophore. In some fish- and reptilespecies the color changes are chiefly regulated by the nervous system, in others by hormones or by both.

In the present paper we will draw special attention to the regulation of the migration of the pigment granules in the melanophores of amphibia, in which the principal control of the color change is hormonal and in which neurogenic factors play, if any, a very unimportant role.

\section{HORMONES CONTROLLING PIGMENT DISPERSION}

Melanophore Stimulating Hormones (MSH's). ${ }^{1}$ From the extensive literature on $\mathrm{MSH}$, reviewed among others by Parker (1948), Landgrebe et al. (1955) and Voss (1960), it appears on one hand that MSH is present in the pituitary glands of nearly all vertebrates investigated so far, and on the other that there are considerable differences in the pigment stimulating potencies of various pituitary extracts. As all MSH-preparations used up to 5 years ago were impure, these differences may be explained by contamination.

It was of great importance that recently investigations in pigment cell biology received considerable support from biochemical sides. Especially the application of modern technics like counter-current distribution, electrophoresis and chromatography made the purification, isolation, and determination of the chemical structure of MSH possible. Thousands of pituitary glands from pigs, beef, and sheep formed the starting material for these fundamental investigations, which revealed not only the existence of three different MSH's, but also the exact amino acid sequences of these hormones (Lee and Lerner, 1956; Harris and Roos, 1956; Harris and Lerner, 1957; Geschwind et al.. 1957a,b). These MSH's received the names: $\alpha-\mathbf{M S H}$, glutamyl- $\beta$-MSH and seryl- $\beta$-MSH.

These important findings raised many interesting problems, some of which were put already by Geschwind (1959). For instance, the question had to be answered, whether one or more than one type of

\footnotetext{
${ }^{1}$ Synonyms are for example intermedin, B(= blackening) hormone, pigment dispersing hormone and chromatophorotropic hormone. In the present paper we will use the term melanophore stimulating hormone (MSH).
} 
MSH is found in a single pituitary gland, and also whether still other MSH's than the three, mentioned above, exist.

As a matter of fact, working with single pituitaries of pigs, beef, and sheep, Burgers (1960, 1961) demonstrated that three MSH's are present in the pituitaries of each of these animals, and that the electrophoretic behavior of these hormones is similar to that of $\alpha-\mathrm{MSH}$, glutamyl- $\beta-\mathrm{MSH}$ or seryl- $\beta-\mathrm{MSH}$, respectively. Further, the existence and the chemical structure of MSH's, other than those mentioned so far, were detected in the human (Harris, 1959) and horse pituitaries (Dixon and Li, 1961).

For investigations into the relation of the chemical structure and biological activity of MSH the amphibian melanophore proved to be an excellent test-object. This follows among others from the fact that nearly all information about the pigment dispersing potencies of various MSHmolecules has been obtained by means of an assay, based on the photoelectric measurement of the darkening of a piece of Rana pipiens-skin (Shizume et al., 1954).

From a comparative endocrinological standpoint it is desirable to have information on the nature of the MSH or MSH's of poikilotherm Vertebrates. With this in view Burgers (1960) studied the electrophoretic behavior of batches of intermediate lobes of the bull-frog, Rana catesbeiana. As a matter of fact three different compounds with MSH-activity were found: the electrophoretic behavior of one of these was similar to that of seryl- $\beta$-MSH, of the second to that of $\alpha-\mathrm{MSH}$, whereas the behavior of the third was different from any of the MSH's known at that moment (autumn of 1959). The chemical structure of these hormones could not be determined. It may be assumed that the MSII's produced in frog's pituitaries possess such chemical structures that they are maximally apt to induce a pigment dispersion reaction in amphibian melanophores.

Adrenocorticotropic Hormones ( $A C T H$ 's). The pigment dispersing activity of ACTHpreparations was discovered by Sprague et al. (1950) when experimenting with hypophysectomized frogs. His observations were confirmed by many others, of whom Johnsson and Högberg (1952) and Sulman (1952) suggested that ACTH and MSH are identical. The results of the experiments of various other investigators (Morris, 1952; Geschwind et al., 1952; Karkun et al., 1953; and Benfey et al., 1954), however, showed that ACTH and MSH have distinctly different biochemical properties. It was, therefore, concluded that the pigment dispersing activity of ACTH was attributable to contamination of ACTH with MSH.

Further the experiments of de Wied and Gaarenstroom (1953) and of Dixon (1956) showed that highly purified ACTH-preparations still possess a pigment dispersing action; consequently, it was assumed that ACTH has an intrinsic melanophore stimulating activity.

On comparing the chemical structure of ACTH (a polypeptide consisting of 39 amino acids (Li et al., 1955) with that of $\alpha$-MSH (13 amino acids; Lee and Lerner, 1956), it appeared that the sequence of the 13 amino acids of $\alpha-\mathrm{MSH}$ is identical with that of the 13 amino acids at the C-terminal of the ACTH-molecule; thus the melanophore dispersing property of ACTH found its explanation.

It must be stressed that the ACTHpreparations tested on amphibian melanophores were all of mammalian origin; consequently, it is not certain whether the ACTII, present in the frog's pituitary gland (Geschwind et al., 1952), plays a role in the color change of this animal. It will, therefore, be of much interest to investigate the chemical properties and structures of this hormone in poikilotherm vertebrates.

The fact that pigment dispersion in amphibian melanophores can be caused by such different molecules as ACTH $(39$ amino acids), both $\beta$-MSH's (18 amino acids each) and $\alpha$-MSH (13 amino acids) has further raised the question whether only a part of the polypeptide is essential for the pigment reaction. Schwyzer and $\mathrm{Li}$ (1958) investigated therefore numerous synthetic polypeptides, and found among others that the pentapeptide L-His-I-Phe- 
L-Arg-L-Try-Gly possesses some pigment dispersing potency. This amino acid sequence is present in ACTH, as well as in $\alpha$ - and in both $\beta$-MSH's. As Rana pipiensskin was used as a test-object, it was concluded that the pigment migration in the melanophores of this frog can be induced by even a pentapeptide.

\section{HORMONES CONTROLLING PIGMENT CONCENTRATION}

Adrenaline. By the end of the 19th century adrenaline was already known to act on the amphibian melanophore. Corona and Moroni (1898) and later Lieben (1906) found that it has a strong pigment concentrating effect in larval and adult amphibia, which fact was confirmed by
Kulemann (1960) demonstrated that explanted embryonic Xenopus-melanophores also react with pigment dispersion following adrenaline administration.

As there is no appreciable difference in melanophore reaction to injected adrenaline in normal Xenopus, adapted to a white background and in hypophysectomized Xenopus, this pigment dispersion cannot be the result of an increased secretion of MSH by the pituitary gland under the influence of the adrenaline. This view is supported by in vitro experiments, in which isolated webs from the same animal were immersed in adrenaline- and in control saline-solutions. The results of this experiment are shown in Fig. 2, from which it appears that the M.I.'s of the melano-<smiles>CNCC(O)c1ccc(O)c(O)c1</smiles><smiles></smiles><smiles>CCOC(C)=O</smiles>

Fig. 1. Formulas of adrenaline, serotonin, and melatonin.

many others [cf. Parker (1948, p. 196)]. According to Burgers et al. (1953), however, adrenaline can have also a melanophore dispersing effect in Xenopus. As a matter of fact these workers found, using the melanophore index (M.I.) of Hogben and Slome (1931): (1) The melanophores of normal Xenopus, adapted to a black background (M.I. 4.8-5.0) react, following adrenaline administration, with pigment concentration until an intermediate pigment dispersing state (M.I. \pm 3.0) is reached, whereas those of other amphibia concentrate completely under the influence of this hormone; (2) Adrenaline, injected into normal Xenopus, adapted to a white background, induces a distinct pigment dispersion in the melanophores, a phenomenon unknown in other amphibian species. This was confirmed by Hudson and Bentley (1955) in adult toads, whereas phores of isolated webs from normal light adapted animals increase distinctly under the influence of adrenaline, whereas the M.I.'s of control webs in saline slightly decrease (Van Oordt and Burgers, 1958). As the possibility that the skin secretion interfered with this reaction could be excluded (cf. p. 104), it was assumed that in Xenopus adrenaline has a direct pigment dispersing effect on melanophores with concentrated pigment granules.

Other Pigment Concentrating Hormones. $W$-hormone. The experiments of Hogben and Slome (1931, 1936) with Rana fuscigula and Xenopus laevis led these workers to assume the existence of two melanophore stimulating hormones, the first being $\mathrm{MSH}$, which is formed in the intermediate lobe of the pituitary and induces pigment dispersion, and the second, the s.c. W.(= whitening) hormone, which is pro- 
duced in the pars tuberalis of the pituitary gland and causes pigment concentration.

This viewpoint was shared by Steggerda and Soderwall (1939), who found that cauterization of the pars tuberalis of Rana pipiens abolished a complete pigment concentration, and supposed this to be due to the absence of a pigment concentrating hormone in the cauterized part of the pituitary gland. Extracts of the pars tuberalis is present which has a pigment concentrating effect on the melanophores of amphibian larvae. These observations were confirmed by Beall et al. (1937) working with Xenopus-tadpoles, and by Bors and Ralston (1951) using larval and adult Xenopus in vivo and Xenopus-skin in vitro.

The principle acting on the melanophores was recently isolated from beef

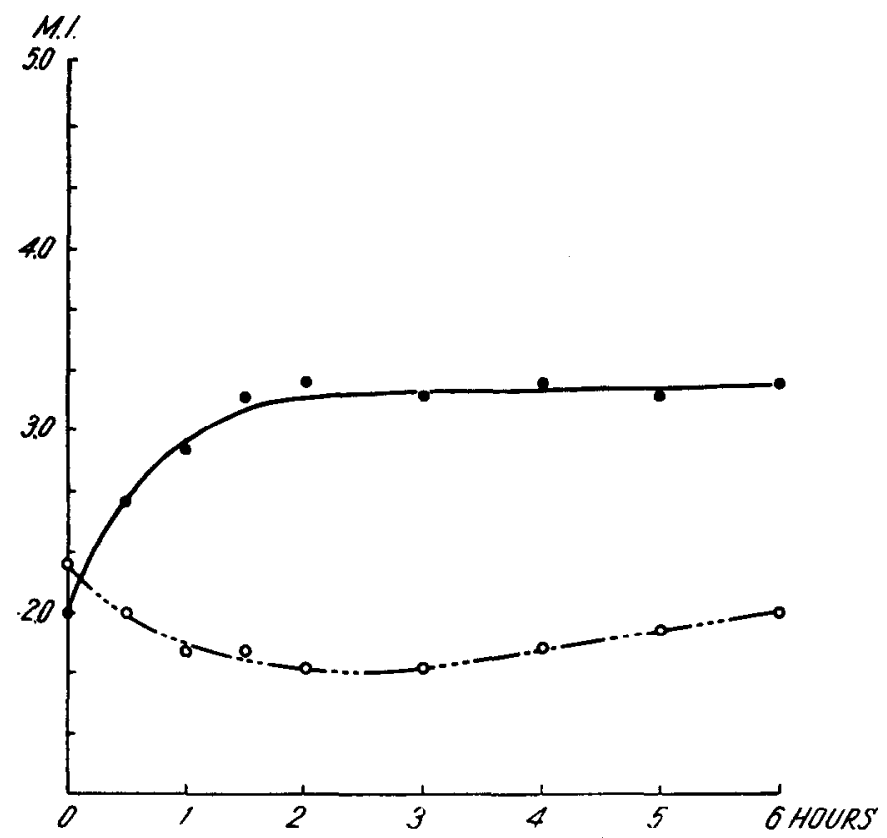

Fig. 2. Graph, showing M.I.-curves of melanophores in isolated webs of normal Xenopus (adapted to a white background), and immersed in adrenaline (solid line) or in saline solution (broken line).

with a pigment concentrating potency, however, have never been obtained, as it is obviously very difficult to prepare MSHfree extracts of such a minute part of the pitnitary gland. Parker and Scatterty (1937), however, were of opinion that only one hormone, namely MSH, is involved in the color change processes, and that blanching of the amphibia is caused by the loss of MSH from the blood.

Melatonin. ${ }^{2}$ The classical investigations of McCord and Allen (1917) showed that in the mammalian pineal gland a principle

2 The melatonin (batchnumber U-12.884) used in these experiments was kindly supplied by the Upjohn Company, Kalamazoo, Michigan (U. S. A.). pineals by Lerner et al. (1958), who named it melatonin; its chemical structure (Fig. 1) was determined as $\mathrm{N}$-acetyl-5-methoxytryptamine (Lerner and Case, 1959).

The biological assay for melatonin developed by Mori and Lerner (1960) is based on the pigment migrations in the melanophores of Rana pipiens-skin in vitro. Using tadpoles of Xenopus laevis, Burgers et al. (unpublished) have recently studied the effect of melatonin on melanophores in vivo. It was found that tadpoles, adapted to a black background, display a marked pigment concentration when placed in aquarium water containing melatonin; consequently the results of Bagnara (1960) were confirmed. 
The M.I. of the melanophores of such tadpoles reached its minimal value in about $20 \mathrm{~min}$; thereupon the M.I. gradually increased again. To establish whether this phenomenon was due to inactivation of the melatonin in the aquarium water another group of tadpoles was placed in the same water, $3 \mathrm{hr}$ later (see Fig. 3). As it appeared that the M.I. of the animals of the second group showed the same M.I.changes as those of the initial group, it was concluded that the melatonin was not crease of the M.I. (from 5.0 to 4.3). Mori and Lerner (1960) were able to detect $10^{-11} \mathrm{~g}$ of melatonin by using a photoelectric arrangement for measuring the light transmission through a piece of Rana pipiens-skin pretreated with caffein and Supniewski et al. (1960) were able to determine a quantity of $2.10^{-9} \mathrm{~g}$ melatonin by observing the changes in the $M$. I. of the melanophores in the web of Rana temporaria following injection with melatonin.

It may, therefore, be concluded that

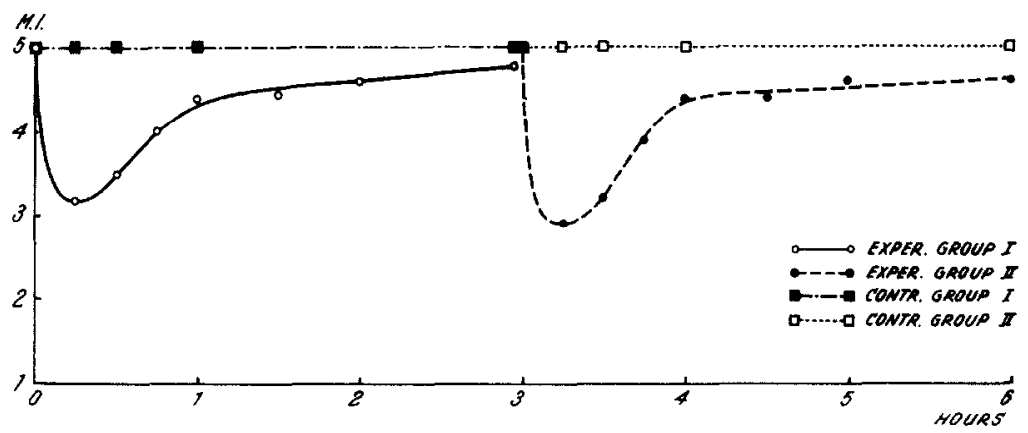

FIG. 3. Graph, showing the melanophore changes in different groups of Xenopus tadpoles, adapted to a black background and swimming in melatonin $\left(10^{-3} \mu \mathrm{g} / \mathrm{ml}\right)$ or in tapwater. For further details see text.

inactivated. Consequently the cause of the pigment dispersion in the melanophores of tadpoles exposed for over $20 \mathrm{~min}$ to a melatonin solution must be ascribed to internal processes, which counteract the pigment concentrating effect of melatonin.

The results of our experiments concerning the time relation of the melanophore reaction induced by melatonin confirm those of Supniewski et al. (1960), who noted that in adult Rana temporaria the pigment concentration, induced by an injection of melatonin, disappears quickly after 30 to $40 \mathrm{~min}$. Thus, our results are comparable with those of McCord and Allen (1917), Huxley and Hogben (1922) and Bors and Ralston (1951), who tested crude mammalian pineal extracts in tadpoles of Rana pipiens, Rana temporaria and Xenopus laevis, respectively.

In another experiment the sensitivity of the melanophores of Xenopus to melatonin was determined. It was found that a dose of $10^{-10} \mathrm{~g} / \mathrm{ml}$ still induces a distinct de- normal tadpoles of Xenopus laevis, adapted to a black background rank among the most sensitive test objects for the in vivo bioassay of melatonin.

The significance of the melatonin present in the mammalian body is still obscure, for its only biological activity, known so far, is its action on amphibian melanophores. Moreover, it has not yet been demonstrated whether or not melatonin is present in the pineals of the lower Vertebrates. With respect to color change reactions in amphibia the pineal gland may play a role, for according to Simonnet et al. $(1952,1954)$ adult specimens of Rana esculenta become considerably darker following pinealectomy, and subsequently pale after administration of extracts of (sheep) pineals.

Moreover, Bagnara (1960) investigating the color change reactions in tadpoles of Xenopus laevis found that the strong pigment concentration in the melanophores of the head and of the myotomes, which these 
larvae exhibit when placed in complete darkness did not occur following pinealectomy.

As several investigators, e.g. Thieblot (1947) and Moskowska (1951), suggested that in mammals the pineal gland inhibits the production of certain hormones in, or their release from the pituitary gland, it might be possible that in frogs the pineal gland impedes the intermediate lobe to secrete its MSH. A direct influence of the secretion products of the pineal gland on the melanophores is, however, also probable.

\section{EXCITEMENT REACTIONS AND SKIN SECRETION}

During preliminary investigations into the color changes of Xenopus we noticed (Burgers et al., 1953) that in several respects Xenopus appears to be an exception among the amphibia. For nearly all frogs investigated react to excitement stimuli, e.g. rough-handling or the prick of a needle, with a distinct pallor, which conveniently may be called excitement-pallor. Following excitement stimuli, however, Xenopus shows a darkening reaction (Burgers et al., 1953; Ketterer and Remilton, 1954), which as far as we are aware is among amphibia found only in the flying frog, Polypedates reinwardtii (Siedlecki, 1909).

It was also observed that excitement stimuli induce an abundant release of skin secretion. It was, therefore, assumed that the excitement darkening reaction might be mediated by a substance present in the skin secretion.

This secretion is produced in a large number of macroscopically discernable skin glands. Each gland is connected to the exterior with a narrow duct. Two kinds of glands can be distinguished: large ones filled with short microscopical needle-like crystals, consisting of a protein-like substance, and small ones, containing mucus. According to Spannhof (1954) the mucous glands release their contents continuously, whereas the sticky substance of the protein glands is only secreted following cer- tain stimuli. By a simple procedure, i.e. by massaging the skin of normal adult Xenopus or by exposing the animal to ether-vapor, which causes the animal to release the contents of these glands, one can easily collect this secretion which appeared to consist mainly of the product of the protein glands.

Injection of skin seeretion extracts induce pigment dispersion in Xenopusmelanophores with concentrated pigment. As this extract also has a pigment dispersing effect on the melanophores of isolated webs - which only contain some small mucous glands-it was concluded that in skin secretion a substance is present, which acts directly on the melanophores (Burgers, 1956; Burgers and Van Oordt, 1956).

In our studies on the relation of the chemical structure and the melanophore stimulating activity of the phenylalkyl amines it appeared that only the catecholamines, possessing two OH's in the 3,4position at the phenylnucleus, are able to induce pigment dispersion in the melanophores. These and other studies suggested that the pigment dispersing agent in Xenopus skin secretion is a compound possessing a phenylnucleus with two $\mathrm{OH}-$ groups in the 3,4-position (Burgers, 1956).

This hypothesis, however, had to be rejected since it has been found recently in our laboratory by Van de Veerdonk (1960) and by Van de Veerdonk et al. (1961) that the pigment dispersing activity of the skin secretion is due to serotonin. ${ }^{3}$ In connection with this it is interesting that $\mathrm{Kahr}$ and Fischer (1957) described a dispersing effect in Rana temporaria after application of serotonin in vivo. This was confirmed by Davey (1959) in Rana pipiens. Lerner et al. (1958) and Wright and Lerner (1960), however, have described a concentrating effect of serotonin on the pigment granules in the melanophores of the same species in vitro.

\footnotetext{
${ }^{3}$ Moreover, a second indole-compound (bufotenidin) was detected in the same extract; it, however, lacked any pigment dispersing properties.
} 


\section{THE EFFECT OF LIGHT}

In addition to the various substances which have an action on pigment migrations in the melanophores of Xenopus, another factor must be mentioned which also affects the melanophores, namely light.

Bles (1905) found that in young Xenopus-larvae the pigment granules in the melanophores of the head disperse in light, whcrcas in darkness they concentrate. The pigment in the melanophores of the tailfin, however, shows reverse reactions: in light the melanin granules concentrate and in darkness they disperse.

In 1957 Bagnara, repeating these experiments, observed that in isolated tails of Xenopus-larvae placed in darkness for at least $30 \mathrm{~min}$, the pigment granules in the tailfin melanophores disperse completely; when transferred into light such tailfins become transparent in 5 to 7 minutes. These observations were independently confirmed by Van der Lek et al. (1958). Recently Van der Lek (unpublished) studying the spectral sensitivity of this phenomenon found among others that in light with a wave length of more than $650 \mathrm{~m} \mu$, the pigment migrations in the melanophores are similar to those of melanophores kept in complete darkness.

In order to determine whether light causing pigment concentration is absorbed in the melanophores themselves, Van der Lek illuminated single melanophores with a light beam having a diameter of about $100 \mu$. In Fig. 4(a) the illuminated area is shown just prior to the experiment; in Fig. 4 (b) the situation is visible $5 \mathrm{~min}$ later.

From these figures it can be seen that the pigment in all branches of a melanophore concentrates when a certain partin this case about a third-of it is exposed to light (see melanophore $n r$ 1) and illumination of a much smaller part results in only a local effect: the pigment

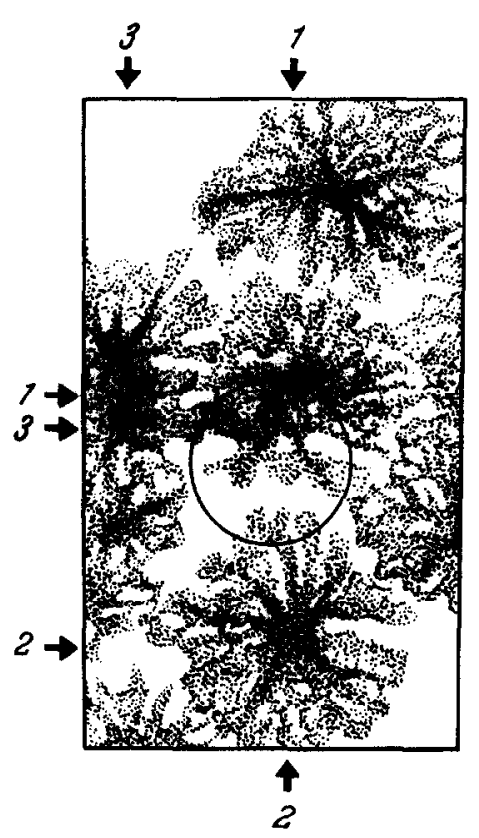

(a)

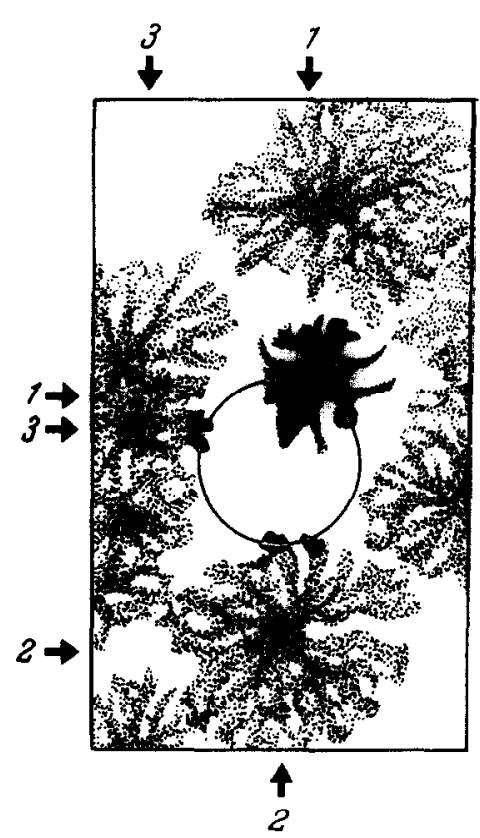

(b)

FIG. 4. The local effect of a narrow light beam on melanophores in the isolated tailfin of a Xenopustadpole kept in complete darkness. (a) Just prior to exposure to the light beam; (b) Five minutes later. 
granules migrate from the illuminated area and accumulate near its border (see melanophores, nrs 2 and 3 ).

It is not likely that the reaction in the nonilluminated parts of melanophore $\mathrm{nr} 1$ is due to the influence of stray light for other melanophores, situated at the same distance of the light-beam, did not react at all.

The results of these experiments indicate: (1) At least a part of the melanophore must be illuminated in order to induce a pigment concentration reaction; (2) This reaction is restricted to a small part of the melanophore, if only a small area of it is illuminated, whereas pigment concentration occurs in the whole cell, if a larger area is exposed to light.

As far as we know the local effect of light on a single melanophore has not previously been investigated in vertebrates. In invertebrates, however, Yoshida (1956) studied the effect of a very narrow light-beam on the pigment migration in a melanophore of the sea urchin Diadema setosum, a species in which the pigment of the melanophores is concentrated in darkness and dispersed in light. When a light-beam with a diameter of only some $\mu$ was directed to a place near such a con- centrated pigment mass, it induced the pigment granules to migrate into the illuminated part of the melanophore-process.

From the above it can be concluded that in Xenopus laevis as well as in Diadema setosum light has a direct effect on the melanophores, resulting in Xenopus in a pigment concentrating and in Diadema in a pigment dispersing reaction.

Finally Van der Lek found that when melanophores with dispersed pigment granules were illuminated for only a few seconds a temporary pigment concentration took place after a short latent period; this period appeared among others to be dependent on the temperature. For example, when isolated Xenopus-tails were kept at a temperature of $22^{\circ} \mathrm{C}$ and a certain light stimulus was given, the melanophores reacted after about $1 \mathrm{~min}$; at $12^{\circ} \mathrm{C}$ the reaction was only visible after $3 \mathrm{~min}$, and at $4^{\circ} \mathrm{C}$ the same light stimulus had no visible effect at all (Fig. 5). When, however, in the latter case the temperature was increased in some tails from $4^{\circ} \mathrm{C}$ to $22^{\circ} \mathrm{C}, 15$ min after the light stimulus had been given, a pigment concentration occurred as yet. This indicates that even at low temperatures light causes certain changes in the melanophores, the visible

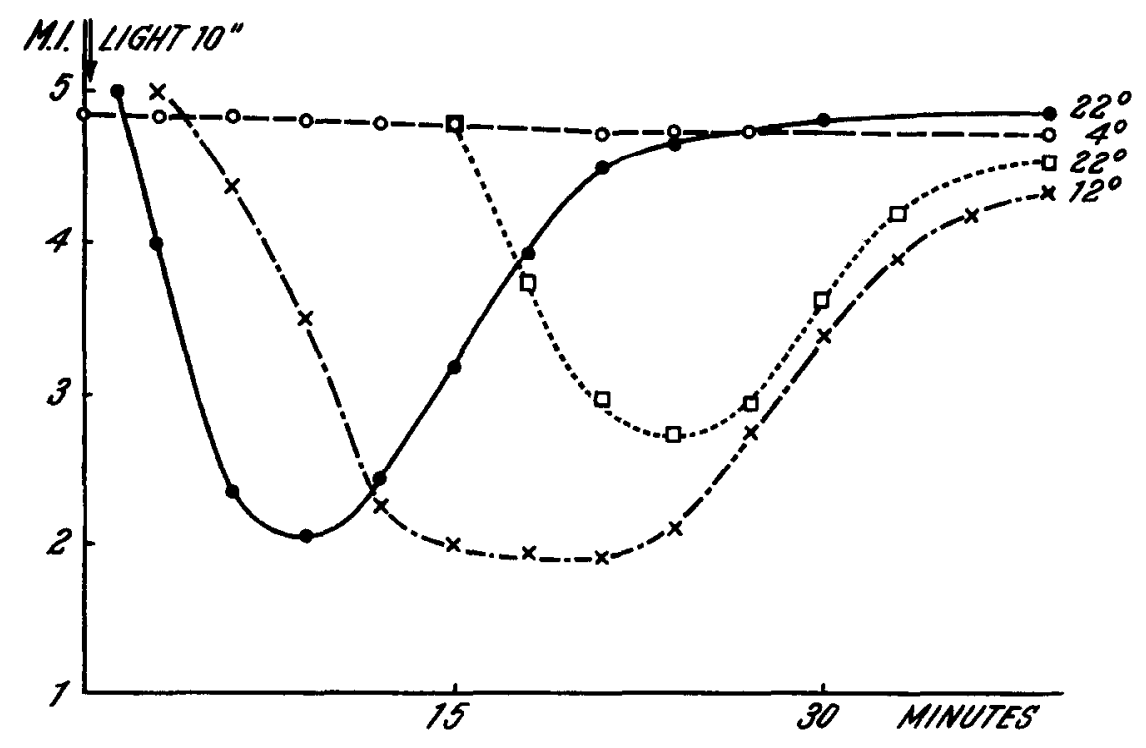

Fig. 5. Graph, showing the effect of temperature on melanophore changes in isolated tailfins of Xenopus kept in complete darkness after illumination during 10 seconds. 
effect of which can be observed at temperatures high enough to permit the pigment migration processes to take place.

In view of the rapid development in the field of protein chemistry it may be expected that before long relative large quantities of highly purified and even synthetic melanophore stimulating hormones (MSH's) will be available to carry out fundamental research in pigment cell biology on a wide scale.

As the pigment migration processes induced by these hormones can be easily observed in the living melanophore, this object is highly appropriate for studies in hormonal action on the cellular level. From the outline given above it is clear that the amphibian melanocyte may be considered the test-object by preference for such investigations.

\section{REFERENCES}

Blgnara, J. T. (1957). Proc. Soc. Exptl. Biol. Med. 94572.

Bagnara, J. T. (1960). Science 132, 1481.

Beall, D., Shapiro, H. A., and Zwarenstein, H. (1937). Chem. and Ind. 56, 190.

Benfey, B. G., Saffran, M., and Schally, A. V. (1954). Nature 174, 1106.

Bues, E. J. (1905). Trans. Roy. Soc. Edinburgh 41, 789.

Bors, O., and Ralston, W. C. (1951). Proc. Soc. Exptl. Biol. Med. 77, 807.

Buraers, A. C. J. (1956). Investigations into the action of certain hormones and other substances on the melanophores of the SouthAfrican Clawed Toad, Xenopus laevis. Thesis, Utrecht.

Buraers, A. C. J. (1960). Abstract 1st Intern. Congr. Endocrinol. Copenhagen 165, 329.

Bunaers, A. C. J. (1961). Endocrinology 68, 698.

Burgers, A. C. J., ANd VAN OoRdT, G. J. (1956). Acta Endocrinol. 23, 265.

Burgers, A. C. J., Boschman, Th. A. C., and VAN de Kamer, J. C. (1953). Acta Endocrinol. 14, 72.

Conuna, A., And Moroni, A. (1898). Reforma Medica 14.

Davey, K. G. (1959). Nature 183, 1271.

Dixon, H. B. F. (1956). Biochim. et Biophys. Acta 19, 392.

Drxon, J. S., AND LI, Ch. H. (1961). Gen. and Comp. Endocrinol. 1, 161.

Gesch wind, I. I. (1959). In "Comparative En- docrinology" (A. Gorbman, ed.), 421. Wiley, New York.

Geschwind, I. I., ReinhardT, W. O., AND II, CH. H. (1952). Nature 169, 1061.

Geschwind, I. I., Li, Ch. H., and Barnaft, L. (1957a). J. Am. Chem. Soc. 79, 620.

Geschwind, I. I., Li, Ch. H., and Barnafi, L. (1957b). J. Am. Chem. Soc. 79, 1003.

Harris, J. I. (1959). Nature 184, 167.

Harris, J. I., AND Roos, P. (1956). Nature 178, 90.

Harris, J. I., and Lerner, A. B. (1957). Nature 179, 1346

Hogben, L., and Slome, D. (1931). Proc. Roy. Soc. B108, 10.

Hogben, L., and Slome, D. (1936). Proc. Roy. Soc. B120, 158.

Hudson, B., And Bentley, G. A. (1955). Lancet 775.

Huxley, J. S., and Hogben, L. T. (1922). Proc. Roy. Soc. B93, 36.

Johnssun, S., AND HögBerg, B. (1952). Nature 169, 286

KAHR, H., AND FIScher, W. (1957). Klin. Wochschr. 35, 41.

KarkUN, J. N., Kar, A. B., AND MUKerdi, B. (1953). Acta Endocrinol. 13, 188.

Ketterer, B., AND Remilton, E. (1954). J. Endocrinol. 11, 7.

Kulemand, H. (1960). Zool. Jahrb. Abt. Allgem. Zool. Physiol. Tiere 69, 169.

Landgrebe, F. W., Ketterer, B., and Waring, H. (1955). In "The Hormones" (G. Pincus and K. N. Thimann, eds.); Yol. 3, p. 389. Academic Press, New York.

LeE, T. H., AND Lerner, A. B. (1956). J. Biol. Chem. 221, 943.

Lerner, A. B., And Case, J. D. (1959). J. Am. Chem. Sac. 81, 6084.

Lerner, A. B., Case, J. D., Takahashi, Y., Lee, T. H., ANd Mori, W. (1958). J. Am. Chem. Soc. 80, 2587.

Li, Ch. H., Geschwind, I. I., Cole, R. D., RaAcke, I. D., Harris, J. I., and Dixon, J. S. (1955). Nature 176, 687.

Lieben, S. (1906). Zentr. Physiol. 20, 108.

MCCord, C. P., ANd Allen, F. P. (1917). J. Exptl. Zool. 23, 207.

MorI, W., AND Lerner, A. B. (1960). Endocrinology 67, 443.

Morris, C. J. O. R. (1952). Lancet, 1210.

Moskowska, A. (1951). Compt. rend. soc. biol. $145,847$.

Parker, G. H. (1948). "Animal Colour Changes and their Neurohumours." University Press, Cambridge.

Parker, G. H., and Scatterty, L. E. (1937). $J$. Cellular Comp. Physiol. 9, 297. 
SchwYZer, R., AND LI, CH. H. (1958). Nature 182, 1669 .

Shizume, K., Lerner, A. B., and Fitzpatrick, T. B. (1954). Endocrinology 54, 553.

SiedleckI, M. (1909). Biol. Zentr. 26, 704.

Simonnet, H., Thieblot, L., and Segal, V. (1952). Ann. endocrinol. 13, 340.

Simonnet, H., Thieblot, L., Melik, T., and Segal, V. (1954). Acta Endocrinol. 17, 402.

SPANNHOF, L. (1954). Wiss. Z. Humboldt Univ. Berlin 3, 295.

Sprague, R. G., Power, M. H., Mason, H. L., Albert, A., Mathieson, D. R., Henck, D. Ph. S., Kendall, E. C., Slocumb, Ch. H., AND Polmy, H. F. (1950). Arch. Internal Med. 85, 199.

Steggerda, F. R., and Soderwall, A. L. (1939). J. Cellular Comp. Physiol. 13, 31.

Sulman, F. G. (1952). Nature 169, 588.

Supniewski, J., Marczynski, T., and Misztal, S. (1960). Bull. acad. polon. sci. VI 8, 483.

Thieblot, L. (1947). J. physiol. (Paris) 39, 321. Van der LeK, B., de Heer, J., Burgers, A. C. J., and Van Oordi, G. J. (1958). Acta Physiol. et Pharmacol. Neerl. 7, 409.

VAN de VeERdonK, F. C. G. (1960). Nature 187, 948.

Van de VeerdonK, F. C. G., Hutsmans, J. W., AND AdDin K, A. D. F. (1961). Z. vergleich. Physiol. 44, 323.

VAN Oordt, G. J., ANd Burgers, A. C. J. (1958). Arch. néerl. zool. Suppl. 13, 290.

Voss, H. E. (1960). In "Fermente, Hormone, Vitamine" (R. Ammon and W. Dirscherl, eds.), Vol. 2, 664. G. Thieme, Stuttgart.

de Wied, D., and Gaarenstroom, J. H. (1953). Acta Endocrinol. 12, 361.

Wright, M. R., ANd Lerner, A. B. (1960). Endocrinology 66, 599.

Yoshida, M. (1956). J. Exptl. Biol. 33, 119.

\section{DISCUSSION}

Bagnara: I should like to expound a bit on the relationships betwecn light and the pineal body in the regulation of pigmentation in Xenopus and other amphibian larvae. First of all, just as you say, the tail melanophores are primarily regulated by the absence of light, however, one wonders why these tail melanophores are contracted under normal illumination, for they are exposed to chromatotropic hormone from the pituitary. Apparently, they are less sensitive to hypophyseal stimulation than the body melanophores which are expanded under normal conditions of illumination. The tail darkening reaction which occurs when $X$ enopus larvae are placed in the dark is due to a photochemical substance which is slowly produced in the tail. It lakes about $30 \mathrm{~min}$ for the accumulation of enough of this substance to cause expansion of tail melanophores. Upon exposure to light, this substance is destroyed in just a few minutes, thus, the tail melanophores contract in 5 to $7 \mathrm{~min}$. Because of this direct sensitivity to light of the tail melanophores, it was thought that the contraction of the body melanophores which results when larvae are placed in the dark was also a direct melanophore reaction to light. However, body lightening begins in just a few minutes and the subsequent return to the expanded condition requires almost an hour. These time factors are not consistent with the concept of a photochemical regulation, but suggest instead the sudden release of a stored substance which is active immediately, but which requires a long time for destruction or for inactivation by normal metabolic processes in the body. Because of the recent emphasis placed upon the action of the pineal body as a light receptor and because of the known action of pineal substance, especially melatonin, in causing melanophore contraction, I have proposed the following hypothesis (Science, November 1960) to explain the regulation of the body lightening reaction which occurs in almost all amphibian larvae after relatively short periods in the dark. The absence of light stimulates the pineal to release its stored melatonin or some related substance, thus leading to the quick onset of body lightening. The long recovery corresponds to a slow disappearance of this compound from the circulation. With respect to such a mechanism it would be necessary for the pineal hormone to be active in extremely small amounts. This is the case for melatonin, the minimal effective dose of which is 0.0001 $\mu \mathrm{g} / \mathrm{ml}$ of aquarium water in which Xenopus larvae swim. Xenopus embryos at the time when melanophores first differentiate (stage 36 of Nieuwkoop and Faber) are sensitive to melatonin, and moreover, melanophores contract on such embryos when they are placed in the dark.

I might summarize my comments by saying that melanophore regulation is a complex phenomenon. Thus, the specific state of melanophores at any given time is the net result of the action of the hypophysis, the pineal, and the direct effect of light on the chromatophores.

VAN OoRd: We like to thank Professor Bagnara for his most interesting remarks, and it is nice to hear that his results are in full agreement with ours.

Welsh: (1) What is the relation between serotonin and the secretion of the large glands of 
frog skin? (2) What role, if any, does the serotonin of amphibian skin play in color changes?

VAN OORDT: (1) The mechanism of skin secretion and the possible role played by serotonin in it was not studied by us. The presence of serotonin in the large skin glands could be proved chemically. (2) It is our opinion that serotonin may be responsible for the darkening of Xenopus in the excilement darkening reaction.

Novales: I agree with Dr. Welsh that the picture with regard to serotonin is confusing. As to melatonin, I have found it to be a potent MSH antagonist on the isolated frog skin. It also contracts the cultured embryonic Ambystoma melanophore. However, thus far serotonin has expanded the cultured Ambystoma melanophore. Perhaps the divergent results are due to doseresponse situation, which should be investigated on the isolated skin and cultured cell. In relation to the expanding action of epinephrine on the cultured Xenopus melanophore, this contracts the cultured Ambystoma and Tarida melanophore, thus the different responses of Xenopus and the other species are due to inherent differences at the cellular level.

VAN OORDT: As far as serotonin is concerned, we regard the pigment dispersing reaction induced by serotonin as a nonspecific one.

Lo: When we were purifying $\beta$-MSH from bovine and equine pituitary glands by a countercurrent distribution, we found out that there were two fractions having MSH activities. A slow moving component shows a very low activ- ity : $8 \times 10^{7} \mu / \mathrm{gm}$ (in vitro frog skin assay), while a fast moving component has normal activity: $2 \times 10^{\circ} \mu / \mathrm{gm}$. The differences in chemical structure between these two components were found to be that slower moving, less active fraction contains one molecule of methionine sulfoxide instead of methionine. When the methionine sulfoxide analog was reduced with large excess of cystein- $\mathrm{HCl}$, the activity was enhanced to $1.2 \times 10^{9} \mu / \mathrm{gm}$. In other words, there are two forms of $\beta$-MSH; oxidized form and reduced form, and the oxidation-reduction site is located on methionine-methionine sulfoxide. The same phenomena were also observed in cases of $\alpha-\mathrm{MSH}$ and adrenocorticotropin.

VAN OORDT: I like to thank Dr. Lo for his most interesting remarks. We are wondering whether or not methionine sulfoxide MSH is present in nature.

Mori: I would like to add a short comment concerning the difference between serotonin and melatonin. Fortunately, I was in Dr. Lermer's laboratory at the time when isolation of melatonin was accomplished, and I did the assay work of melatonin. First, I tried to use serotonin as the standard for biological assay, but I found that serotonin sometimes did not show any lightening effect on the frog skin. $\Lambda$ s far as I know, the difference in the effect on the frog skin between serotonin and melatonin is as follows: melatonin always causes lightening in the frog skin, while serotonin has variable effects on the frog skin, bringing about either a marked lightening, no color change, or a slight darkening. 